\title{
PENELITIAN CAMPURAN ASPAL BETON MENGGUNAKAN PASIR VULKANIK GUNUNG KELUD DENGAN LIMBAH BOTOL PLASTIK
}

\author{
${ }^{1 *}$ Cici Sri Isma Evrilyana, ${ }^{2}$ Ahmad Ridwan, ${ }^{3}$ Yosef Cahyo Setianto \\ Fakultas Teknik Universitas Kadiri \\ Email : ${ }^{1 *}$ cicisri@gmail.com, 2 ahmad ridwan@unik-kediri.ac.id, ${ }^{3}$ yosef.cs@unik-kediri.ac.id
}

\begin{abstract}
The use of a plastic bottle waste mixture on asphalt concrete as an additional material for road pavement is one of the alternatives to get a good quality pavement layer. As well as the innovation of using Mount Kelud volcanic sand as a substitute for Brantas sand. This addition also aims to reduce the amount of plastic waste that is difficult to decipher, in order to reduce the presence of waste so that it does not cause bad impacts on society. This study aims to determine the characteristic properties of asphalt with a mixture of plastic bottle waste. The results of the study, the addition of plastic bottle waste by $2 \%, 3 \%$, and $5 \%$ can be concluded that the addition of $2 \%$ plastic bottle waste cannot meet the specifications, but with the addition of plastic bottle waste 3\% - 5\% it can meet the requirements for the laston mixture specification $(A C-B C)$.
\end{abstract}

Keywords $\quad$ : Concrete Asphalt, Plastic Bottle Waste, Marshall Test, Highway

\begin{abstract}
Abstrak
Penggunaan campuran limbah botol plastik pada aspal beton sebagai material tambahan perkerasan jalan salah satu alternatif yang digunakan untuk mendapatkan kualitas lapis perkerasan yang baik. Serta inovasi penggunaan pasir vulkanik gunung kelud sebagai pengganti pasir brantas. Penambahan ini juga bertujuan untuk mengurangi banyaknya sampah plastik yang sulit diuraikan, agar dapat mengurangi keberadaan sampah sehingga tidak menyebabkan dampak buruk bagi masyarakat. Penelitian ini bertujuan mengetahui sifat sifat karakteristik aspal dengan campuran limbah botol plastik. Hasil Penelitian penambahan limbah botol plastik sebesar $2 \%, 3 \%$, dan $5 \%$ dapat disimpulkan dengan penambahan platik sebesar $2 \%$ belum dapat memenuhi spesifikasi, namun dengan penambahan limbah botol plastik 3\% - 5\% dapat memenuhi syarat spesifikasi campuran laston (AC-BC).
\end{abstract}

Kata kunci : Aspal Beton, Limbah Botol Plastik, Marshall Test, Jalan Raya 


\section{PENDAHULUAN}

\subsection{Latar Belakang}

Aspal beton memiliki sifat - sifat tahan terhadap keausan,kedap air,mempunyai nilai struktural,stabilitas tinggi,dan mudah pelaksanaannya[1][2][3]. Namun pada keadaan tertentu jenis perkerasan ini sering menimbulkan masalah terutama pada kekakuan lapisan dan umur rencana yang tidak seperti diharapkan[4][5]. Selain itu terdapat faktor - faktor lain yang menyebabkan perkerasan di Indonesia tidak bisa mencapai umur rencana, hal ini disebabkan oleh iklim tropis dan beban kendaraan yang sukar dikendalikan[6][7][8]. Penggunaan limbah botol plastik sebagai campuran dapat memperoleh sifat - sifat plastik yang diinginkan dengan cara kopolimerisasi,laminasi,dan ekstrusi[9][10]. Plastik merupakan polimer yang mempunyai keunggulan yaitu sifatnya kuat tapi ringan, tidak karatan dan bersifat termoplastis serta dapat diberi warna.. Dengan demikian setelah dilakukan pengujian pada Lab Teknik Sipil Universitas Kadiri penggunaan Limbah Botol Plastik ini diharapkan akan menambah daya tahan lapis perkerasan aspal terhadap kerusakan yang disebabkan oleh air dan cuaca.

\subsection{Identifikasi Masalah}

Identifiakasi masalah pada tugas akhir ini melakukan pengamatan untuk objek penelitian secara terkontrol dengan menggunakan limbah botol plastik yang sebagai bahan campuran pada perkerasan jalan.

\subsection{Rumusan Masalah}

Sesuai dengan latar belakang dan identifikasi masalah tersebut diatas, maka dapat diangkat rumusan masalahnya adalah:

1. Bagaimanakah pengaruh nilai marshall setelah dilakukan penambahan limbah botol plastik pada berat benda uji?

2. Berapakah hasil optimum pengujian marshall benda uji pada variasi penambahan limbah botol plastik sejumlah 2\%,3\%, dan 5\% dari berat benda uji?

3. Berapa persentase nilai yang dihasilkan volume rongga udara (VIM) pada penambahan limbah botol plastik?

4. Berapa persentase nilai yang dihasilkan volume pori antara butir agregat (VMA) pada penambahan limbah botol plastik?

5. Berapa persentase nilai yang dihasilkan antara butir agregat yang terisi aspal (VFB) pada penambahan limbah botol plastik?

\section{METODE PENELITIAN}

\subsection{Tinjauan Umum}

Menunjang fungsinya sebagai konstruksi jalan, maka perkerasan jalan raya dibuat berlapis-lapis agar mempunyai daya dukung dan keawetan yang memadai[11][12][13]. Lapis 
perkerasan itu terdiri dari lapis permukaan sebagai lapis paling atas yang terdiri dari lapis aus (Wearing Course) dan lapis antara (Binder Course)[14][15]. Lapis pondasi atas (Base Course) yang terletak diantara lapis permukaan dan lapis pondasi bawah[16][17]. Lapis pondasi bawah (Subbase Course) yang terletak diantara lapis pondasi dan tanah dasar. Semua lapis perkerasan tersebut memiliki spesifikasi tersendiri untuk menunjang fungsinya masing-masing sebagai lapis perkerasan.

\subsection{Aspal Berpori (Porous)}

Aspal porus adalah aspal yang dicampur dengan agregat tertentu yang setelah dipadatkan mempunyai $20 \%$ pori-pori udara[18]. Aspal porus umumnya memiliki nilai stabilitas Marshall yang lebih rendah dari beton aspal yang menggunakan gradasi rapat, stabilitas Marshall akan meningkat bila gradasi terbuka yang digunakan lebih banyak fraksi halus[19][20].

\subsection{Limbah Botol Plastik (PET)}

Sampah plastik sebagai campuran aspal bertujuan agar dapat mengurangi sampah plastik yang sulit terurai pada tanah,pemanfaatan ini diharapkan adanya inovasi dari penggunaan limbah plastik menjadi campuran aspal yang lebih baik ini dapat menjadi solusi tepat dalam mengatasi permasalahan sampah di Indonesia. Jenis botol plastik yang digunakan dalam penelitian ini adalah botol plastik dengan kode 1 pada bagian bawah botol, yaitu Polyethylene terephtalate yang sering disebut PET.

\subsection{Alur Penelitian}

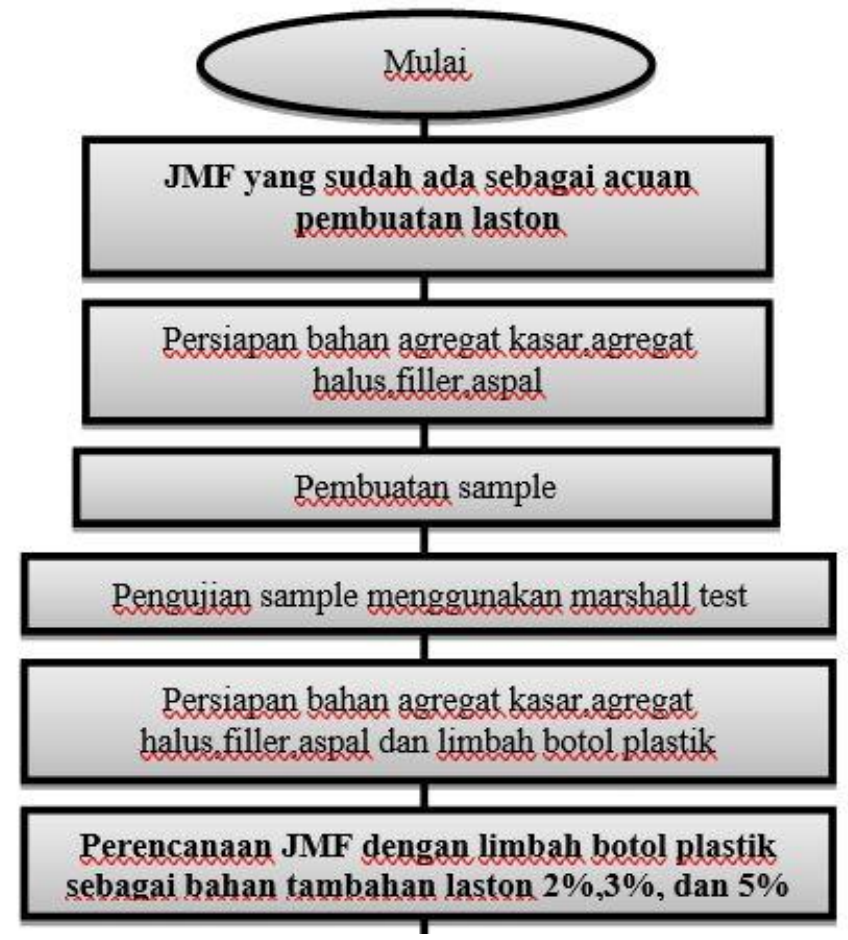




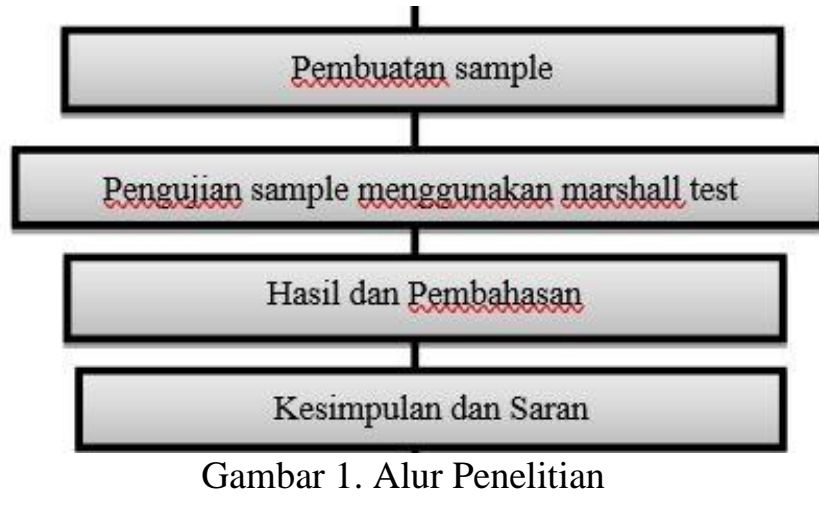

\subsection{Alat Penelitian}

Peralatan yang digunakan dalam penelitian ini adalah sebagai berikut:

1. Satu Set Saringan (Sieve)

2. Alat Uji Pemeriksaan Aspal. (Daktilitas)

3. Alat Uji Pemeriksaan Agregat.

Peralatan yang digunakan antara lain mesin Los Angeles (tes abrasi), alat pengering yaitu oven, timbangan, alat uji berat jenis.

\subsection{Bahan Penelitian}

Bahan-bahan yang digunakan pada penelitian ini adalah:

1. Agregat Kasar dari material batu koral

2. Agregat Halus menggunakan pasir Vulkanik Gunung Kelud

3. Aspal

4. Filler menggunakan Semen Gresik

5. Bahan Tambahan Limbah Botol Plastik

\subsection{Tahap Penelitian}

Tahap-tahap penelitian yang akan dilakukan mulai dari awal sampai akhir seperti yang dijelaskan sebagai berikut:

1. Persiapan Bahan.

2. Persiapan JMF (Job Mix Formula)

Dalam penelitian kali ini mengunakan JMF ( Job Mix Formula ) yang sudah ada.

Tabel 1. Proporsi Campuran AC-BC

\begin{tabular}{|c|c|cc|cc|cc|}
\hline No & Bahan & \multicolumn{2}{|c|}{ Jumlah \% } & \multicolumn{2}{|c|}{ Individual } & \multicolumn{2}{|c|}{ Comulative } \\
\hline 1 & Agragat Kasar & 25 & $\%$ & 300 & gram & 300 & gram \\
\hline 2 & Agragat Medium & 33 & $\%$ & 396 & gram & 696 & gram \\
\hline 3 & Agragat Halus & 40 & $\%$ & 480 & gram & 1176 & gram \\
\hline 4 & Filler & 2 & $\%$ & 24 & gram & 1200 & gram \\
\hline
\end{tabular}


Sumber : (Data (JMF) Job Mix Formula Acuan)

Tabel 2. Penyesuaian Proporsi Campuran AC-BC

\begin{tabular}{|c|c|cc|cc|cc|}
\hline No & Bahan & \multicolumn{2}{|c|}{ Jumlah \% } & \multicolumn{2}{c|}{ Individual } & \multicolumn{2}{c|}{ Comulative } \\
\hline 1 & Agragat Kasar & 23.43 & $\%$ & 281 & gram & 281.2 & gram \\
\hline 2 & Agragat Medium & 30.92 & $\%$ & 371 & gram & 652.2 & gram \\
\hline 3 & Agragat Halus & 37.48 & $\%$ & 450 & gram & 1102 & gram \\
\hline 4 & Filler & 1.87 & $\%$ & 22 & gram & 1124 & gram \\
\hline 5 & Aspal & 6.3 & $\%$ & 76 & gram & 1200 & gram \\
\hline
\end{tabular}

Sumber : (Data (JMF) Job Mix Formula Acuan)

\section{PEMBAHASAN}

\subsection{Hasil Pemesriksaan Karakteristik Aspal}

Syarat minimum temperature titik nyala oleh Bina Marga untuk aspal PEN 60 - 70 (200

$\left.{ }^{\circ} \mathrm{C}\right)$. Titik nyala dan titik bakar aspal perlu diketahui karena Sebagai indikasi temperatur, pemanasan maximum dimana masih dalam batas-batas aman pengerjaan.

Tabel 3. Tabel Pemeriksaan

\begin{tabular}{|c|c|c|c|c|c|c|c|}
\hline \multirow{3}{*}{ No } & \multirow{3}{*}{ Jenis Pemeriksaan } & \multirow{2}{*}{\multicolumn{3}{|c|}{$\begin{array}{c}\text { Hasil } \\
\text { Kadar Plastik } \\
\end{array}$}} & \multicolumn{2}{|c|}{ Spesifikasi } & \multirow{3}{*}{ Sat. } \\
\hline & & & & & \multirow{2}{*}{$\min$} & \multirow{2}{*}{$\max$} & \\
\hline & & $2 \%$ & $3 \%$ & $5 \%$ & & & \\
\hline 1 & Berat Jenis & 1,03 & 1,02 & 1,01 & \multicolumn{2}{|c|}{$\geq 1$} & $\mathrm{gr} / \mathrm{cc}$ \\
\hline 2 & Daktilitas & 112,75 & 105 & 101,42 & \multicolumn{2}{|c|}{$\geq 100$} & $\mathrm{~cm}$ \\
\hline 3 & Titik Nyala & 284 & 268 & 254 & \multicolumn{2}{|c|}{$\geq 232$} & ${ }^{\circ} \mathrm{C}$ \\
\hline 4 & Titik Lembek & 50,23 & 49,72 & 51,6 & \multicolumn{2}{|c|}{$\geq 48$} & ${ }^{\circ} \mathrm{C}$ \\
\hline 5 & Kehilangan Berat & 0,062 & 0,074 & 0,085 & \multicolumn{2}{|c|}{$\leq 0,8$} & $\%$ \\
\hline
\end{tabular}

Sumber : Laboratorium Fakultas Teknik Universitas Kadiri

\subsection{Data Dan Perhitungan}

Tabel 4. Data Tinggi Dan Diameter Benda Uji

\begin{tabular}{|c|c|c|c|c|c|c|c|c|}
\hline $\begin{array}{l}\mathrm{Kad} \\
\text { ar } \\
\text { Aspa } \\
1(\%)\end{array}$ & $\begin{array}{c}\text { Berat } \\
\text { Aspal } \\
\text { (gr) }\end{array}$ & $\begin{array}{l}\text { Kada } \\
\quad \text { r } \\
\text { Plasti } \\
\text { k (\%) }\end{array}$ & $\begin{array}{l}\text { Berat } \\
\text { Plasti } \\
\text { k (gr) }\end{array}$ & $\begin{array}{c}\text { Ting } \\
\text { gi } \\
\text { Asp } \\
\text { al } \\
\text { (cm) }\end{array}$ & $\begin{array}{l}\text { Tingg } \\
\text { i Rata } \\
\text { - rata } \\
(\mathrm{cm})\end{array}$ & $\begin{array}{c}\text { Diamete } \\
\text { r Aspal } \\
(\mathrm{cm})\end{array}$ & $\begin{array}{l}\text { Diamet } \\
\text { er rata } \\
\text { - rata } \\
(\mathrm{cm})\end{array}$ & $\begin{array}{l}\text { Volume } \\
\text { (m3) }\end{array}$ \\
\hline \multicolumn{9}{|c|}{ Hasil ukur sampel benda uji kadar $2 \%$} \\
\hline $5 \%$ & $60 \mathrm{gr}$ & $2 \%$ & $24 \mathrm{gr}$ & 7,2 & 6,92 & 10,12 & 10,12 & 578,846 \\
\hline
\end{tabular}




\begin{tabular}{|c|c|c|c|c|c|c|c|c|}
\hline $5 \%$ & $60 \mathrm{gr}$ & $2 \%$ & $24 \mathrm{gr}$ & 6,9 & & 10,12 & & 554,728 \\
\hline $5 \%$ & $60 \mathrm{gr}$ & $2 \%$ & $24 \mathrm{gr}$ & 6,5 & & 10,12 & & 522,569 \\
\hline $5 \%$ & $60 \mathrm{gr}$ & $2 \%$ & $24 \mathrm{gr}$ & 7,3 & & 10,12 & & 586,886 \\
\hline $5 \%$ & $60 \mathrm{gr}$ & $2 \%$ & $24 \mathrm{gr}$ & 6,7 & & 10,12 & & 538,649 \\
\hline \multicolumn{9}{|c|}{ Hasil ukur sampel benda uji kadar 3\% } \\
\hline $5 \%$ & $60 \mathrm{gr}$ & $3 \%$ & $36 \mathrm{gr}$ & 7,1 & \multirow{5}{*}{7,02} & 10,12 & \multirow{5}{*}{10,12} & 570,807 \\
\hline $5 \%$ & $60 \mathrm{gr}$ & $3 \%$ & $36 \mathrm{gr}$ & 7,3 & & 10,12 & & 586,886 \\
\hline $5 \%$ & $60 \mathrm{gr}$ & $3 \%$ & $36 \mathrm{gr}$ & 7 & & 10,12 & & 562,767 \\
\hline $5 \%$ & $60 \mathrm{gr}$ & $3 \%$ & $36 \mathrm{gr}$ & 6,8 & & 10,12 & & 546,688 \\
\hline $5 \%$ & $60 \mathrm{gr}$ & $3 \%$ & $36 \mathrm{gr}$ & 6,9 & & 10,12 & & 554,728 \\
\hline \multicolumn{9}{|c|}{ Hasil ukur sampel benda uji kadar $5 \%$} \\
\hline $5 \%$ & $60 \mathrm{gr}$ & $5 \%$ & $60 \mathrm{gr}$ & 6,7 & \multirow{5}{*}{6,82} & 10,12 & \multirow{5}{*}{10,12} & 538,649 \\
\hline $5 \%$ & $60 \mathrm{gr}$ & $5 \%$ & $60 \mathrm{gr}$ & 6,5 & & 10,12 & & 522,569 \\
\hline $5 \%$ & $60 \mathrm{gr}$ & $5 \%$ & $60 \mathrm{gr}$ & 6,9 & & 10,12 & & 554,728 \\
\hline $5 \%$ & $60 \mathrm{gr}$ & $5 \%$ & $60 \mathrm{gr}$ & 7,2 & & 10,12 & & 578,846 \\
\hline $5 \%$ & $60 \mathrm{gr}$ & $5 \%$ & $60 \mathrm{gr}$ & 6,8 & & 10,12 & & 546,688 \\
\hline
\end{tabular}

Sumber : Laboratorium Fakultas Teknik Sipil Universitas Kadiri

Tabel 5. Kadar Limbah Botol Plastik 2\%,3\%,dan 5\%

\begin{tabular}{|c|c|c|c|c|c|}
\hline \multicolumn{2}{|c|}{$\begin{array}{l}\text { kadar limbah } \\
\text { plastik } 2 \%\end{array}$} & \multicolumn{2}{|c|}{$\begin{array}{l}\text { kadar limbah } \\
\text { plastik 3\% }\end{array}$} & \multicolumn{2}{|c|}{$\begin{array}{l}\text { kadar limbah } \\
\text { plastik 5\% }\end{array}$} \\
\hline sampel 1 & 1206,12 & sampel 1 & 1261,85 & sampel 1 & 1310,52 \\
\hline sampel 2 & 1226,53 & sampel 2 & 1223,71 & sampel 2 & 1289,47 \\
\hline sampel 3 & 1244,89 & sampel 3 & 1243,29 & sampel 3 & 1273,68 \\
\hline sampel 4 & 1219,38 & sampel 4 & 1203,09 & sampel 4 & 1216,84 \\
\hline sampel 5 & 1258,16 & sampel 5 & 1256,7 & sampel 5 & 1292,63 \\
\hline \multicolumn{2}{|c|}{$\begin{array}{c}\text { kadar limbah 2\% } \\
\text { dan aspal 5\% }\end{array}$} & \multicolumn{2}{|c|}{$\begin{array}{c}\text { kadar limbah 3\% } \\
\text { dan aspal 5\% }\end{array}$} & \multicolumn{2}{|c|}{$\begin{array}{c}\text { kadar limbah 3\% } \\
\text { dan aspal 5\% }\end{array}$} \\
\hline sampel 1 & 24,12 & sampel 1 & 37,85 & sampel 1 & 65,52 \\
\hline sampel 2 & 24,53 & sampel 2 & 36,71 & sampel 2 & 64,47 \\
\hline sampel 3 & 24,89 & sampel 3 & 37,29 & sampel 3 & 63,68 \\
\hline sampel 4 & 24 & sampel 4 & 26,09 & sampel 4 & 60,84 \\
\hline sampel 5 & 25,16 & sampel 5 & 37,7 & sampel 5 & 64,63 \\
\hline
\end{tabular}

Sumber: Laboratorium Fakultas Teknik Universitas Kadiri

Tabel 4.4.7.1. Hasil pengujian karakteristik Marshall untuk kadar 2\%

\begin{tabular}{|c|c|c|c|c|c|c|c|}
\hline no & $\begin{array}{c}\text { Kadar } \\
\text { Plastik }\end{array}$ & VMA & VIM & VFB & Stabilitas & Flow & MQ \\
\hline & $\mathbf{2 \%}$ & $\mathbf{\%}$ & $\mathbf{\%}$ & $\mathbf{\%}$ & $\mathbf{k g}$ & $\mathbf{m m}$ & $\mathbf{~ k g / m m}$ \\
\hline 1 & sampel 1 & 22,04 & 5,68 & 74,21 & 789,19 & 1,72 & 458,83 \\
\hline 2 & sampel 2 & 23,56 & 7,52 & 68,06 & 837,04 & 2,47 & 338,88 \\
\hline 3 & sampel 3 & 22,30 & 6,00 & 73,10 & 777,76 & 2,84 & 273,86 \\
\hline 4 & sampel 4 & 20,69 & 4,05 & 80,41 & 1176,72 & 2,69 & 437,44 \\
\hline 5 & sampel 5 & 22,74 & 6,53 & 71,27 & 824,98 & 1,89 & 436,50 \\
\hline & spesifikasi & $15 \%$ & $3-5 \%$ & $65 \%<$ & $800 \mathrm{~kg}<$ & $2-4$ & min \\
\hline
\end{tabular}




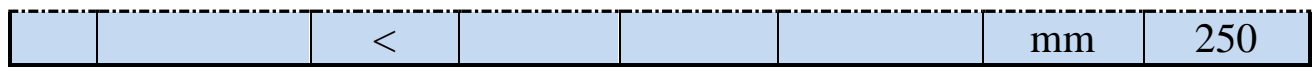

Sumber: Laboratorium Fakultas Teknik Universitas Kadiri

Tabel 4.4.7.2. Hasil pengujian karakteristik Marshall untuk kadar 3\%

\begin{tabular}{|c|c|c|c|c|c|c|c|}
\hline no & adar Plastik & VMA & VIM & VFB & Stabilitas & Flow & MQ \\
\hline & $3 \%$ & $\%$ & $\%$ & $\%$ & kg & $\mathbf{m m}$ & $\mathrm{g} / \mathrm{mm}$ \\
\hline 1 & sampel 1 & 22,37 & 5,12 & 77,10 & 897,54 & 2,23 & 102,49 \\
\hline 2 & sampel 2 & 22,51 & 5,29 & 76,52 & 888,44 & 2,67 & 332,75 \\
\hline 3 & sampel 3 & 21,14 & 3,62 & 82,88 & 834,95 & 2,96 & 282,08 \\
\hline 4 & sampel 4 & 23,10 & 6,01 & 73,99 & 837,04 & 1,65 & 507,29 \\
\hline 5 & sampel 5 & 21,51 & 4,07 & 81,09 & 973,06 & 2,09 & 465,58 \\
\hline & pesifikasi & $5 \%<$ & $3-5 \%$ & $65 \%<$ & $800 \mathrm{~kg}<$ & $2-4 \mathrm{~mm}$ & $\operatorname{hin} 250$ \\
\hline
\end{tabular}

Sumber: Laboratorium Fakultas Teknik Universitas Kadiri

Tabel 4.4.7.3. Hasil Pengujian Karakteristik Marshall Untuk Kadar 5\%

\begin{tabular}{|c|c|c|c|c|c|c|c|}
\hline no & $\begin{array}{c}\text { Kadar } \\
\text { Plastik }\end{array}$ & VMA & VIM & VFB & Stabilitas & Flow & MQ \\
\hline & $\mathbf{5 \%}$ & $\mathbf{\%}$ & $\mathbf{\%}$ & $\mathbf{\%}$ & $\mathbf{k g}$ & $\mathbf{m m}$ & $\mathbf{k g} / \mathbf{m m}$ \\
\hline 1 & sampel 1 & 23,82 & 4,93 & 79,32 & 941,33 & 2,01 & 468,32 \\
\hline 2 & sampel 2 & 24,48 & 5,75 & 76,49 & 983,63 & 1,63 & 603,46 \\
\hline 3 & sampel 3 & 26,61 & 8,41 & 68,39 & 962,48 & 1,67 & 576,34 \\
\hline 4 & sampel 4 & 22,23 & 2,95 & 86,72 & 1008,48 & 2,24 & 450,21 \\
\hline 5 & sampel 5 & 23,50 & 4,53 & 80,74 & 1028,89 & 2,01 & 511,89 \\
\hline & spesifikasi & $\begin{array}{c}15 \% \\
<\end{array}$ & $3-5 \%$ & $65 \%<$ & $800 \mathrm{~kg}<$ & $2-4 \mathrm{~mm}$ & $\begin{array}{c}\text { min } \\
250\end{array}$ \\
\hline
\end{tabular}

Hasil : Laboratorium Fakultas Teknik Universitas Kadiri

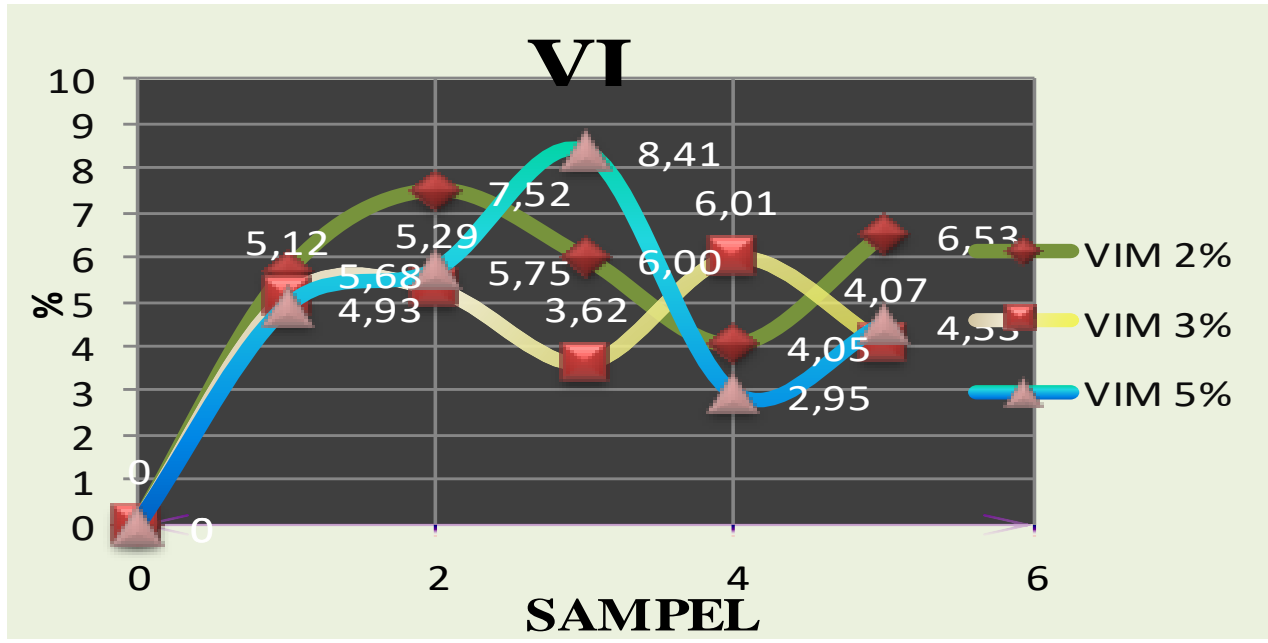

Grafik 1. Hubungan Antara Kadar Limbah Botol Plastik 2\%,3\%,5\% Dengan Nilai VIM 


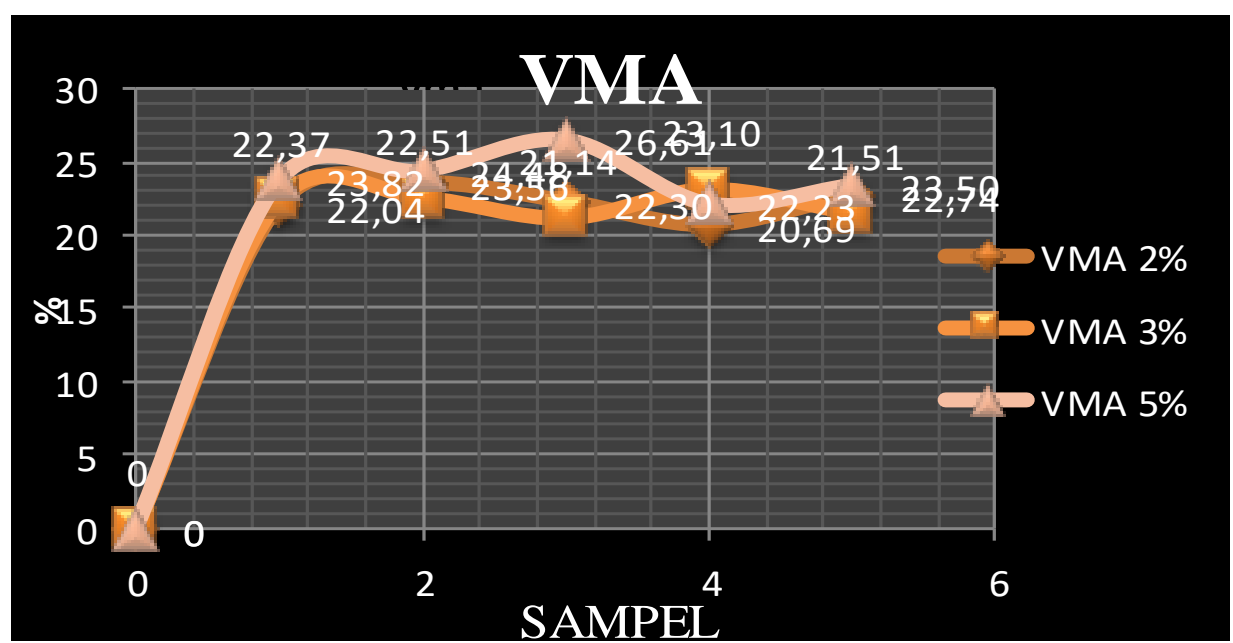

Grafik 2. Hubungan Antara Kadar Limbah Botol Plastik 2\%,3\%,5\% Terhadap Nilai VMA

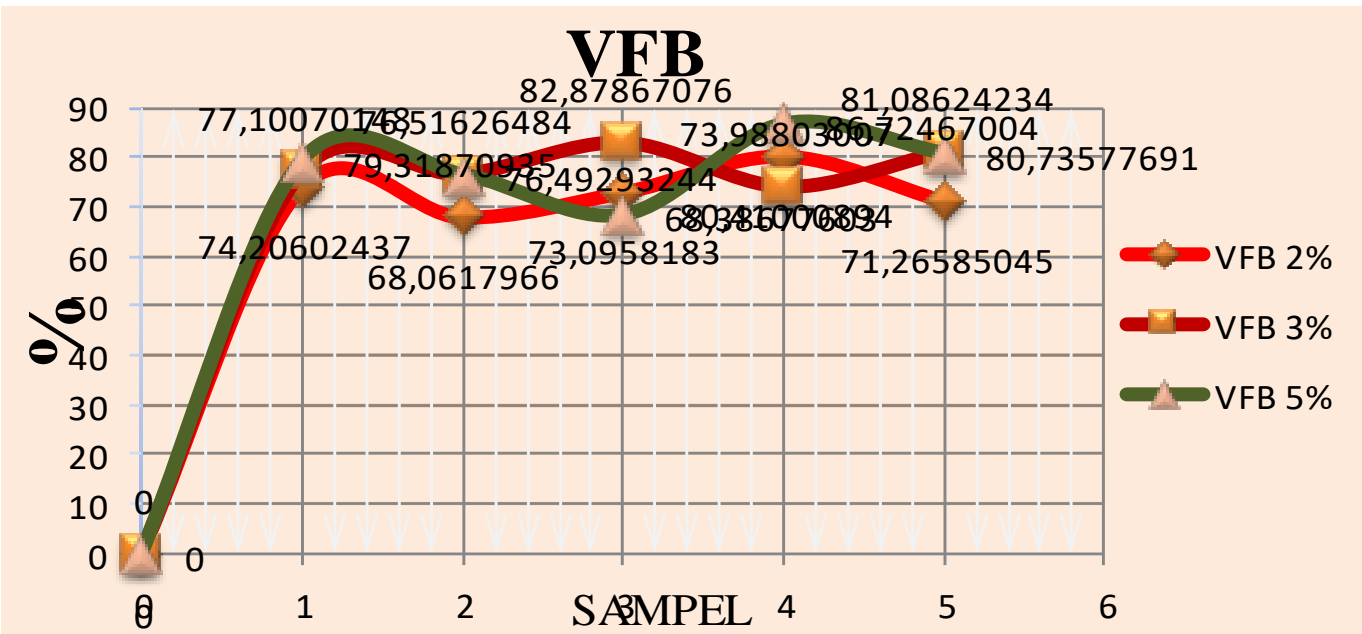

Grafik 3. Memperlihatkan Hubungan Kandungan Limbah Botol Plastic 2\%,3\%,5\% Dengan Nilai VFB

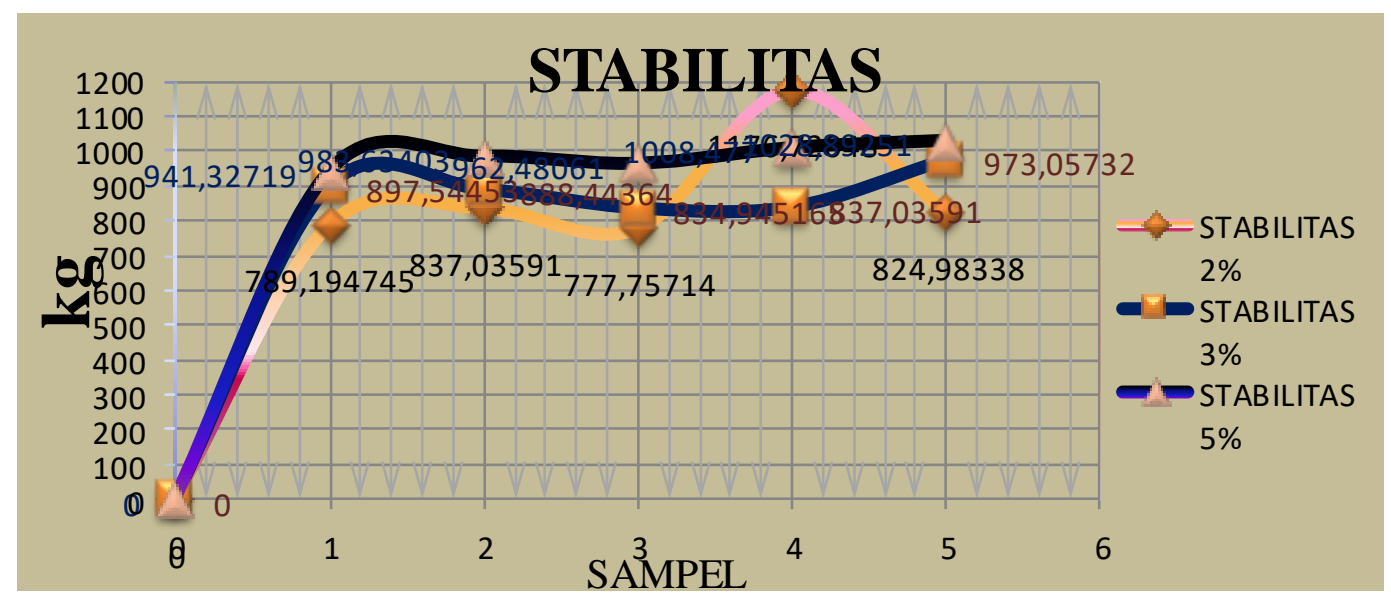




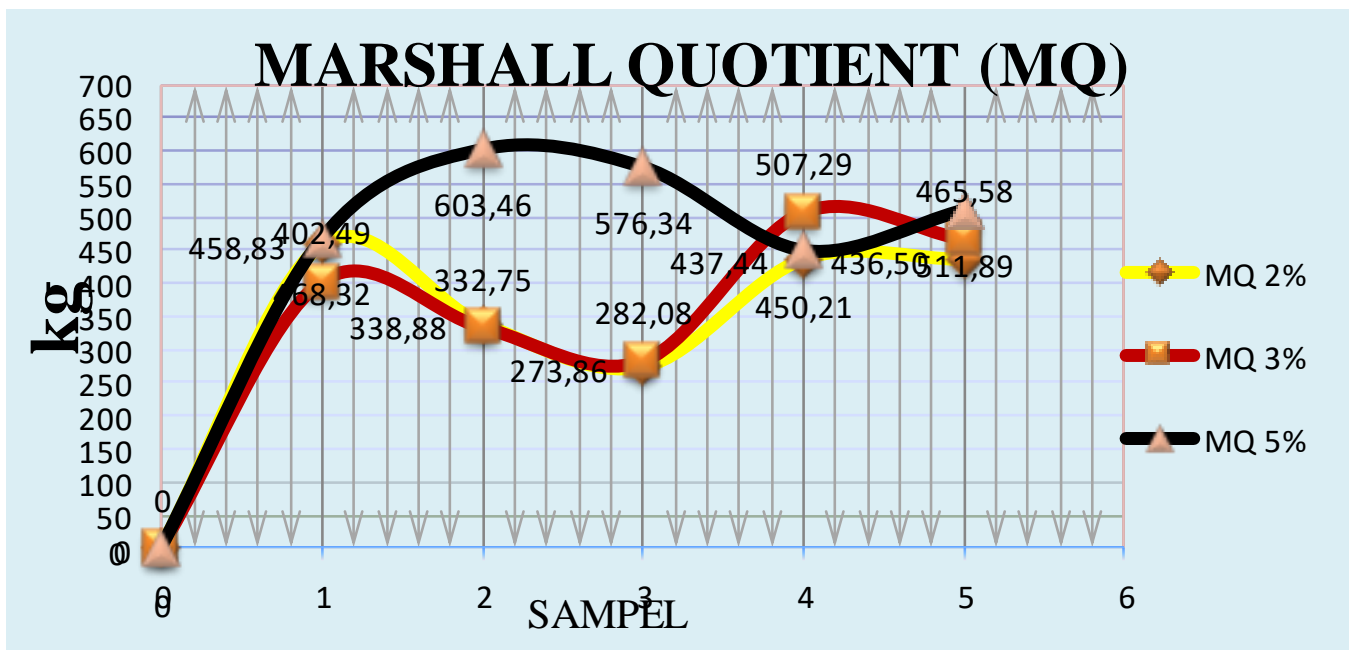

Grafik 5. Quotient Marshall

\section{KESIMPULAN DAN SARAN}

\subsection{Kesimpulan}

Penelitian ini telah dilakukan di Laboratorium Fakultas Teknik Universitas Kadiri. Berdasarkan hasil dan analisa penelitian yang diperoleh, maka dapat ditarik beberapa kesimpulan, yaitu :

1. Penambahan kadar limbah botol plastik pada campuran aspal dengan kadar 2\%,3\%,dan 5\% menghasilkan Stabilitas yaitu : (Kadar 2\% sampel $1=789,19 \mathrm{~kg}$ ), (Kadar 3\% sampel $1=897,54 \mathrm{~kg}),($ Kadar 5\% sampel $1=941,33 \mathrm{~kg}$. Nilai stabilitas pencampuran aspal dengan kadar limbah botol plastik dengan kadar 2\% tidak dapat memenuhi spesifikasi sedangkan kadar 3\%-5\% dapat memenuhi spesifikasi.

2. Penambahan limbah botol plastik pada campuran aspal beton nilai optimumnya adalah kadar $2 \%=503,25 \mathrm{~kg}, \mathrm{kadar} 3 \%=612,96 \mathrm{~kg}$, kadar $5 \%=645,18 \mathrm{~kg}$ mengalami kenaikan.

3. Nilai VIM pada campuran dengan penggunaan plastik (kadar $2 \%=5,68 \%),($ kadar $3 \%$ $=5,12 \%),($ kadar $5 \%=4,93 \%)$. Nilai VIM campuran dengan kadar plastik $2 \%$ hingga 5\% telah memenuhi syarat yang ditetapkan pada spesifikasi umum bina marga 2010.

4. Nilai VMA pada campuran aspal beton kadar plastik $(2 \%=22,04 \%),(3 \%=22,37 \%)$, $(5 \%=23,82 \%)$. Dari nilai tersebut menunjukan dapat dilihat bahwa nilai VIM cenderung mengalami peningkatan. 
5. Nilai VFB pada campuran aspal beton dengan campuran kadar plastik $(2 \%=74,21 \%)$, $(3 \%=77,10 \%),(5 \%=79,32 \%)$. Dari nilai tersebut dapat dilihat bahwa nilai VFB cenderung meningkat, hal ini menunjukan bahwa campuran dengan penambahan limbah botol plastik bersifat kedap sehingga lebih mudah mengalami bleeding saat temperatur meningkat.

\subsection{Saran}

Untuk mengetahui tingkat keawetan campuran laston dengan menggunakan limbah botol plastik, ada baiknya dilakukan pemeriksaan uji durabilitas untuk penelitian selanjutnya.

\section{DAFTAR PUSTAKA}

[1] Faisal, S. M. Shaleh, and M. Isya, "KARAKTERISTIK MARSHALL CAMPURAN ASPAL BETONAC-BC MENGGUNAKANMATERIAL AGREGAT BASALT DENGAN ASPAL PEN. 60/70 DAN TAMBAHAN PARUTAN BAN DALAM BEKAS KENDERAAN RODA 4,” vol. 3, no. 3, pp. 38-48, 2014.

[2] G. S. Muaya, O. H. Kaseke, and M. R. E. Manoppo, "Pengaruh Terendamnya Perkerasan Aspal oleh Air Laut yang Ditinjau Terhadap Karakteristik Marshall,” J. Sipil Statik, vol. 3, no. 8, pp. 562-570, 2015.

[3] D. . Umum, "RSNI Geometri Jalan Perkotaan (RSNI T-14-2004)," Jakarta; Badan Stand. Nas., no. 13, pp. 4-73, 2004.

[4] M. Sanam, R. F. Litelnoni, A. Suraji, B. Aspal, and L. Plastis, "A . Agregat kasar Penyerapan (\%) • Berat Jenis Bulk • Berat Jenis SSD • Berat Jenis App Abrasi dengan mesin Los Angeles (\%) B . Agregat Halus Penyerapan (\%) • Berat Jenis Bulk • Berat Jenis SSD • Berat Jenis App Kadar lumpur (\%) C . Additif,” vol. 21, no. 2, pp. 32-39, 2013.

[5] I. S. Simanjuntak, Y. Riris, and R. Saragi, "Analisa Perbandingan Kualitas Aspal Beton Dengan Filler Bentonite," 2013.

[6] I Nyoman Arya Thanaya, "Studi Karakteristik Campuran Aspal Beton Lapis Aus ( ACWC ) Menggunakan Aspal Penetrasi 60 / 70 dengan Penambahan Lateks Material dan Metode," vol. 22, no. 2, pp. 77-86, 2016.

[7] SNI 03-2417-1991, "Metode pengujian tentang analisis saringan agregat halus dan kasar," pp. 1-5, 1990.

[8] W. J. Korua, O. H. Kaseke, and L. Elisabeth, "Kriteria Marshall Pada Campuran Beraspal Panas Jenis Lapis Aspal Beton-Lapis Aus Bergradasi Halus,” vol. 3, no. 12, pp. 847-852, 2015.

[9] R. Basuki and M. Machsus, "Penambahan Gilsonite Resin Pada Aspal Prima 55 untuk 
Meningkatkan Kualitas Perkerasan Hot Mix,” J. Apl. Tek. Sipil, vol. 3, no. 1, p. 16, 2007, doi: 10.12962/j12345678.v3i1.2564.

[10] Djumari and D. Sarwono, "Perencanaan Gradasi Aspal Porus Menggunakan Material," Media Tek. Sipil, vol. IX, pp. 9-14, 2009.

[11] S. Sukirman, Perkerasan lentur jalan raya, vol. 2. 1999.

[12] S. Sukarman, Beton Aspal Campuran Panas. Yayasan Obor Indonesia, 2003.

[13] E. Nurfadzilah, S. Winarto, and Y. Cahyo, "ANALISA JALAN RING ROAD NGAWI STA 3+200 - STA 6+200 KABUPATEN NGAWI PROPINSI JAWA TIMUR," Jurmateks, vol. 1, no. 1, pp. 33-43, 2018.

[14] A. Kumalawati and M. Y., "Analisis Pengaruh Penggunaan Abu Batu Apung Sebagai Pengganti Filler Untuk Campuran Aspal,” J. Tek. Sipil, vol. II, no. 2, pp. 191-200, 2013.

[15] SNI 03-2417-1991, "Metode Pengujian Keausan Agregat dengan Mesin Abrasi Los Angeles," Balitbang PU, vol. 12, no. 12, pp. 1-5, 1991.

[16] S. N. Indonesia, "Metode pengujian berat jenis dan penyerapan air agregat kasar," SNI03-1969-1990, 1990.

[17] S. N. Indonesia, "Metode Pengujian Keausan Agregat dengan Mesin Abrasi Los Angeles," SNI-03-2417-1991, 1991.

[18] E. Gardjito, "STUDY PERENCANAAN GEOMETRIK, PERKERASAN JALAN DAN PERENCANAAN ANGGARAN BIAYA PADA JALAN RAYA KALIDAWIR-Ds. NGUBALAN Kec. KALIDAWIR," UKaRsT, vol. 1, no. 2, p. 11, 2017.

[19] I. M. A. Ariawan, "PENGGUNAAN BATU KAPUR SEBAGAI FILLER PADA CAMPURAN ASPHALT CONCRETE BINDER COARSE (AC-BC) DENGAN METODE KEPADATAN MUTLAK (PRD),” J. Ilm. Tek. Sipil, 2007.

[20] D. P. Umum, "Metode Pengujian Tentang Analisis Saringan Agregat Halus Dan Kasar SNI 03-1968-1990," Jakarta Badan Pekerj. Umum, 1990. 